\title{
PENDIDIKAN TB MELALUI WHATSAPP REMINDER BERKALA TERHADAP TINGKAT PENGETAHUAN REMAJA DI SMA NEGERI 2 DENPASAR
}

\author{
I Dewa Putu Gede Putra Yasa ${ }^{1}$, I Putu Bayu Suadnyana ${ }^{2}$, N Adi Sumartawan², \\ I Made Widastra ${ }^{4}$ \\ 1,2,3 Jurusan Keperawatan Politeknik Kesehatan \\ Denpasar, Bali, Indonesia
}

E-mail: babaloxo@gmail.com¹, adi_sumartawan@yahoo.co.id²

\begin{abstract}
Tuberculosis that attacks adolescents aged 10-18 years tends to increase. Health education is one way to increase adolescent knowledge about how to prevent tuberculosis, one of the media that can be used for health education is WhatsApp. This study aims to determine the effect of TB education through WhatsApp periodic reminder on the level of knowledge of adolescents in SMA Negeri 2 Denpasar in 2019. The research design used was one-group pre-post test design. The number of samples was 44 people selected by quota sampling technique. The study was conducted in July to August 2019. Data collection used knowledge level questionnaires about TB. The results of this study the average value of knowledge of adolescents before being given health education at 11.68 and after being given health education at 19.02. Hypothesis testing uses paired t-test with $p$ value $=0.001(p<0.05)$. The conclusion of this research is the effect of TB education through WhatsApp periodic reminder on the level of knowledge of adolescents, then it is recommended to do health education using WhatsApp media.
\end{abstract}

Keywords: health education, WhatsApp, adolescent knowledge, tuberculosis

Abstrak : Tuberculosis yang menyerang remaja usia 10-18 tahun cenderung mengalami peningkatan. Pendidikan kesehatan merupakan salah satu cara untuk meningkatkan pengetahuan remaja mengenai cara pencegahan tuberculosis, salah satu media yang dapat digunakan untuk pendidikan kesehatan adalah media WhatsApp. Penelitian ini bertujuan untuk mengetahui pengaruh pendidikan TB melalui WhatsApp reminder berkala terhadap tingkat pengetahuan remaja di SMA Negeri 2 Denpasar tahun 2019. Desain penelitian yang digunakan adalah one-group pre-post test design. Jumlah sampel sebanyak 44 orang yang dipilih dengan teknik quota sampling. Penelitian dilakukan pada bulan Juli sampai Agustus 2019. Pengumpulan data menggunakan kuesioner tingkat pengetahuan mengenai TB. Hasil penelitian ini nilai rerata tingkat pengetahuan remaja sebelum diberi pendidikan kesehatan sebesar 11.68 dan sesudah diberi pendidikan kesehatan sebesar 19.02. Uji hipotesis menggunakan uji paired t-test dengan nilai $\mathrm{p}$ value $=$ $0,001$ ( $\mathrm{p}<0,05)$. Simpulan penelitian ini ada pengaruh pendidikan TB melalui WhatsApp reminder berkala terhadap tingkat pengetahuan remaja, selanjutnya disarankan melakukan pendidikan kesehatan dengan menggunakan media WhatsApp.

Kata kunci : pendidikan kesehatan, WhatsApp, pengetahuan remaja, TB 


\section{PENDAHULUAN}

Tuberculusis (TB) merupakan penyakit yang disebabkan oleh infeksi bakteri Mycobacterium tuberculosis. Penyakit ini dapat menyebar melalui droplet orang yang telah terinfeksi hasil TB. Di seluruh dunia, TB adalah salah satu dari 10 penyebab utama kematian dan penyebab utama dari satu agen infeksius (di atas HIV/AIDS). TB menyebabkan sekitar 1,3 juta kematian (kisaran, 1,2-1,4 juta) pada tahun 2017. Secara global, perkiraan persebaran TB adalah 10,0 juta orang (kisaran, 9,0-11,1 juta) mengembangkan penyakit TB pada 2017: 5,8 juta pria, 3,2 juta wanita dan 1,0 juta anak. Ada kasus di semua negara dan kelompok umur, tetapi secara keseluruhan $90 \%$ adalah orang dewasa (berusia $\geq 15$ tahun), dua pertiga berada di delapan negara: India (27\%), Cina (9\%), Indonesia (8\%), Filipina (6\%), Pakistan $(5 \%)$, Nigeria (4\%), Bangladesh $(4 \%)$ dan Afrika Selatan (3\%) (1).

Tubercolusis masih sangat tinggi di Indonesia, menurut laporan profil kesehatan 2017, jumlah kasus TB tahun 2017 adalah 360.770 kasus, kasus tertinggi terjadi di provinsi Jawa Barat dengan jumlah 78.698 dan yang paling kecil yaitu gorontalo dengan jumlah 754 kasus (2).

Tuberculosis bisa terjadi di semua usia tidak hanya menyerang orang dewasa saja tapi juga sebagian besar menyerang remaja. Tuberculosis yang menyerang remaja usia 10-18 tahun cenderung mengalami peningkatan, pada tahun 2014 berjumlah 10.766 kasus yang mengalami peningkatan di tahun 2015 menjadi 17.018 kasus (16), dan menurut profil kesehatan RI tahun 2017 kasus tuberculosis pada usia 15-24 tahun berjumlah $15,60 \%(56.267)$ dari rata-rata kasus TB nasional(2).

Provinsi Bali menduduki posisi ke 22 dengan jumlah kasus TB sebesar 3.257 dan paling banyak terjadi di Kota Denpasar dengan jumlah kasus 1.021 dan yang terkecil adalah Kabupaten Bangli. SMAN 2 Denpasar merupakan salah satu SMA yang terletak dekat dengan pasar sanglah dan pusat kota denpasar dengan tingkat polusi yang tinggi.

Penelitian yang berjudul pemberian pendidikan kesehatan melalui media leaflet efektif dalam peningkatan pengetahuan perilaku pencegahan Tuberculusis paru di kabupaten ponorogo, menyatakan bahwa dari jumlah 30 responden sebesar $46,7 \%$ memiliki tingkat pengetahuan kurang, 36,7\% memiliki pengetahuan cukup dan hanya $16,6 \%$ responden yang memiliki pengetahuan baik tentang TB (3).

Tuberculosis mempunyai dampak yang sangat luas, tidak hanya berdampak di bidang kesehatan saja tapi juga dari aspek sosial dan ekonomi, dengan demikian TB merupakan ancaman terhadap cita-cita pembangunan dalam meningkatkan kesejahteraan rakyat secara menyeluruh, karenanya perang terhadap TB berarti pula perang terhadap kemiskinan, ketidakproduktifan, dan kelemahan akibat TB(4).

Kementerian Kesehatan RI mempercepat upaya eliminasi TB pada 2030. Akselerasi itu dilakukan melalui akses pencegahan, diagnosis, pengobatan, dan layanan kesehatan bagi seluruh penderita TB, serta meningkatkan pendanaan program TB yang berkelanjutan dan mandiri.

Pemerintah Indonesia melakukan berbagai terobosan dalam mencapai eliminasi TB 2030, antara lain, Standar Pelayanan Minimal (SPM), dimana pemerintah daerah diwajibkan untuk mengalokasikan dana daerah yang memadai. Kemudian melakukan promosi kesehatan deteksi kasus TB secara aktif melalui pendekatan keluarga dan penguatan sistem surveilans dengan 
menghubungkan sistem informasi TB dan sistem informasi fasilitas pelayanan kesehatan, pengembangan respons cepat untuk akses terhadap alat diagnostik dan obat- obatan, meningkatkan secara maksimal manfaat dari Jaminan Kesehatan dengan melakukan sinkronisasi layanan pengobatan $\mathrm{TB}$ dengan JKN, dan penguatan penelitian dan pengembangan terkait pencegahan dan pengendalian $\mathrm{TB}(5)$.

Promosi kesehatan menjadi salah satu solusi utama dalam pencegahan $\mathrm{TB}$, namun upaya tersebut dalam pelaksanaannya masih kurang efektif terutama di kalangan remaja, karena media ceramah dan leflet yang kurang menarik dan tidak mampu menjangkau semua remaja yang ada dengan keterbatasan ruang dan waktu. pada masa serba modern ini keterbatasan ruang dan waktu bukan lagi menjadi masalah(6).

Berkembangnya internet serta aplikasi-aplikasi berbasis internet bukan hal baru lagi dan saat ini sedang diminati oleh kaum remaja, jadi salah satu solusi untuk masalah ini adalah dengan memanfaatkan aplikasi berbasis internet yang lebih efektif dari segi ruang dan waktu salah satunya adalah layanan chatting WhatsApp. Layanan chatting WhatsApp merupakan salah satu aplikasi berbasis internet yang sedang diminati remaja. Whatsapp adalah aplikasi chatting dimana anda bisa mengirim pesan text, suara, gambar, lokasi, bahkan video ke teman- teman menggunakan jenis ponsel apapun. WhatsApp pun dapat digunakan sebagai pengingat/reminder(6).

WhatsApp

pertumbuhan signifikan dengan menghimpun 1,5 miliar pengguna aktif bulanan (7), dengan menggunakan layanan chatting WhatsApp pemberian pendidikan kesehatan tentang Tuberculosis akan mampu lebih efektif serta tidak akan mengalami keterbatasan ruang dan waktu guna meningkatkan pengetahuan remaja terhadap TB.

SMA Negeri 2 Denpasar terletak di pusat kota Denpasar dan berdekatan dengan pasar sanglah yang merupakan daerah yang kurang bersih serta banyak polusi kendaraan dan limbah pasar, oleh sebab itu peneliti memutuskan untuk meneliti di SMA Negeri 2 Denpasar.

\section{METODE}

Penelitian ini menggunakan desain penelitian pre experimental dengan jenis penelitian yang digunakan adalah Onegroup pre-post test design. Penelitian ini telah dilaksanakan di SMAN 2 Denpasar. Populasi dalam penelitian ini adalah remaja kelas X IPS. Jumlah remaja di SMAN 2 Denpasar pada tahun 2019 sebanyak 144 orang dengan jumlah sampel sebanyak 44 orang. Teknik sampling yang digunakan dalam penelitian ini adalah non-probability sampling yaitu quota sampling.

Tingkat pengetahuan diukur menggunakan lembar kuesioner yang terdiri dari 20 pernyataan tentang TB. Uji yang analisis bivariate yang digunakan dalam penelitian ini adalah Paired T-Test karena data berdistribusi normal.

\section{HASIL DAN PEMBAHASAN}

Tabel 1

Distribusi Frekuensi Karakteristik Remaja Berdasarkan Usia di SMA Negeri 2 Denpasar Tahun 2019

\begin{tabular}{lcrl}
\hline No & Usia & f & \% \\
\hline 1 & 15 tahun & 35 & 79,5 \\
2 & 16 tahun & 9 & 20,5 \\
\hline & Jumlah & 44 & 100 \\
\hline
\end{tabular}

Berdasarkan interpretasi table 1 diatas, dari 44 responden didapatkan bahwa sebagian besar yaitu $79,5 \%$ berusia 15 tahun. 
I Dewa Putu Gede Putra Yasa, I Putu Bayu Suadnyana, N Adi Sumartawan, I Made Widastra. Desember 2020. 13 (2). 97-102

Tabel 2

Distribusi Frekuensi Karakteristik Remaja Berdasarkan Jenis Kelamin di SMA Negeri 2 Denpasar Tahun 2019

\begin{tabular}{lccc}
\hline No & J K & F & \% \\
\hline 1 & L & 15 & 34,1 \\
2 & P & 29 & 65,9 \\
\hline & Jumlah & 44 & 100
\end{tabular}

Berdasarkan interpretasi table 2 diatas, dari 44 responden didapatkan bahwa sebagian besar yaitu 65,9 \% berjenis kelamin perempuan.

Tabel 3

Distribusi Pengetahuan Remaja Mengenai

TB Sebelum Diberikan Pendidikan

Kesehatan Melalui WhatsApp

di SMA Negeri 2 Denpasar

Tahun 2019

\begin{tabular}{lccccc}
\hline N & Mean & Median & Modus & $\begin{array}{l}\text { Standar } \\
\text { Deviasi }\end{array}$ & $\begin{array}{l}\text { Min- } \\
\text { Max }\end{array}$ \\
\hline 44 & 11.68 & 12 & 13 & 1.653 & $8-14$ \\
\hline \multicolumn{4}{c}{ Berdasarkan } & interpretasi tabel 3
\end{tabular}

diatas, dari 44 responden didapatkan bahwa rata-rata nilai pengetahuan remaja mengenai TB sebelum diberikan pendidikan kesehatan pendidikan kesehatan melalui WhatsApp yaitu 11.68 dengan nilai terbanyak yaitu 13 dan mediannya yaitu 12 dengan standar deviasi yaitu 1.653 , nilai terendah yaitu 8 dan nilai tertinggi yaitu 14 .

Hasil penelitian dari Wibisono (2017) mengenai efektivitas penggunaan grup sosial media whatsapp sebagai media edukasi penanganan pertama cedera musculoskeletal, menyatakan bahwa ratarata sebelum diberi intervensi diperoleh rerata nilai 6,5 dan sesudah intervensi mengalami peningkatan rerata nilai menjadi 7,83. Remaja SMA menunjukkan ketertarikan yang sangat besar mengenai pendidikan kesehatan, namun hal ini tidak ditunjang dengan sarana pendidikan kesehatan yang efektif dan efisien. Remaja kelas X di SMA N 2 Denpasar belum pernah pendidikan $\mathrm{TB}$, hal ini menyebabkan remaja menjawab kurang tepat terhadap pertanyaan yang diberikan. Remaja kelas $\mathrm{X}$ yang diberikan pendidikan melalu WhatsApp Reminder tampak sangat antusias terbukti dari semua remaja membaca materi yang diberikan, serta meberikan respon balik saat materi dikirimkan.

\section{Tabel 4}

Distribusi Pengetahuan Remaja Mengenai

TB Setelah Diberikan Pendidikan

Kesehatan Melalui WhatsApp

di SMA Negeri 2 Denpasar

Tahun 2019

\begin{tabular}{lccccl}
\hline N & Mean & Median & Modus & $\begin{array}{l}\text { Standar } \\
\text { Deviasi }\end{array}$ & $\begin{array}{l}\text { Min- } \\
\text { Max }\end{array}$ \\
\hline 44 & 19.02 & 19 & 19 & 0.762 & $18-20$ \\
\hline
\end{tabular}

Berdasarkan interpretasi tabel 4

diatas, dari 44 responden didapatkan bahwa rata-rata nilai pengetahuan remaja mengenai TB setelah diberikan pendidikan kesehatan melalui WhatsApp yaitu 19.02 dengan nilai terbanyak yaitu 19 dan mediannya yaitu 19 dengan standar deviasi yaitu 0.762 , nilai terendah yaitu 18 dan nilai tertinggi yaitu 20 .

Upaya dalam meningkatkan pengetahuan remaja dapat dilakukan dengan pendidikan kesehatan. Pendidikan kesehatan dapat dilakukan melalui berbagai media salah satunya media sosial, dimana media sosial merupakan media yang sangat efektif dan dengan biaya yang sangat murah, media ini dapat digunakan secara cepat seiring degan perkembangan jaman untuk melakukan promosi maupun pendidikan kesehatan . Hasil penelitian dari tentang Promosi kesehatan menggunakan gambar dan teks 
I Dewa Putu Gede Putra Yasa, I Putu Bayu Suadnyana, N Adi Sumartawan, I Made Widastra. Desember 2020. 13 (2). 97-102

dalam aplikasi WhatsApp pada kader posbindu yang menyatakan bahwa rerata kepuasan belajar post intervensi edukasi melalui whatsapp lebih tinggi dibandingkan dengan intervensi pesan teks(8).

\section{Tabel 5}

Analisis Bivariat Pengaruh Pendidikan Kesehatan Melalui WhatsApp Reminder Berkala Terhadap Pengetahuan Remaja Mengenai TB di SMAN 2 Denpasar Tahun 2019

\begin{tabular}{lcccc}
\hline Pengetahuan & N & Mean & $\begin{array}{l}\text { Selisis } \\
\text { Mean }\end{array}$ & p Value \\
\hline $\begin{array}{l}\text { Sebelum } \\
\text { pendidikan } \\
\text { kesehatan }\end{array}$ & 44 & 11.68 & & \\
$\begin{array}{l}\text { Setelah } \\
\text { pendidikan } \\
\text { kesehatan }\end{array}$ & 44 & 19.02 & & 0,001 \\
\hline
\end{tabular}

Berdasarkan interpretasi tabel 5 diatas, didapatkan bahwa terjadi peningkatan rata-rata tingkat pengetahuan setelah diberikan pendidikan kesehatan dibandingkan dengan sebelum diberikan pendidikan kesehatan sebanyak 7.341 dengan rerata nilai 11.68 pada saat sebelum diberikan pendidikan kesehatan meningkat menjadi 19.02 setelah diberikan pendidikan kesehatan.

Indonesia merupakan salah satu negara dengan pengguna media sosial terbesar di dunia. Instagram, Facebook dan WhatsApp tetap menduduki peringkat teratas jejaring sosial di Indonesia. Jejaring sosial banyak digunakan untuk bertukar informasi serta menjadi tempat promosi. Metode promosi menggunakan jejaring sosial sangat efektif dan dengan biaya yang sangat murah, media ini dapat digunakan secara cepat seiring degan perkembangan jaman. Penelitian Muntaner (2015) tentang Effects Of A Whatsapp-Delivered Physical Activity Intervention To Enhance Health-Related Physical Fitness
Components And Cardiovascular Disease Risk Factors In Older Adults yang dilakukan di Spanyol, menunjukkan bahwa penggunaan WhatsApp menghasilkan sedikit perubahan pada beberapa komponen kebugaran fisik yang berhubungan dengan kesehatan dan faktor risiko penyakit jantung.

Penggunaan media sosial yang begitu besar sebagai sumber informasi dan promosi mampu memberi pengaruh terhadap tingkat pengetahuan remaja dikarenakan ketergantungan remaja terhadap media sosial terutama WhatsApp sehingga media sosial menjadi sumber informasi terbesar bagi kaum remaja, menjadikan media sosial sebagai wadah yang tepat untuk memberikan promosi maupun pendidikan kesehatan untuk meningkatkan derajat kesehatan remaja.

\section{UCAPAN TERIMAKASIH}

Ucapan terimkasih disampaikan kepada Politeknik Kesehatan Denpasar Jurusan Keperawatan, Dosen Pembimbing, serta Kepala Sekolah SMA N 2 Denpasar dan tema-teman penenliti yang telah membantu dalam penelitian ini.

\section{ETIKA PENELITIAN}

Etika penelitian telah disetujui oleh Komisi Etik Penelitian Kesehatan (KEPK) Poltekkes Denpasar dengan nomor : LB.02.03/EA/KEPK/0389/2019

\section{SUMBER DANA}

Sumber dana pada penelitian kali ini adalah Badan Penelitian Politeknik Kesehatan Denpasar

\section{DAFTAR RUJUKAN}

1. WHO. Global Tuberculosis Report 2018. 2018.

2. Budijanto D. Data dan Informasi Profil Kesehatan Indonesia 2017. Jakarta; 2018. 
I Dewa Putu Gede Putra Yasa, I Putu Bayu Suadnyana, N Adi Sumartawan, I Made Widastra. Desember 2020. 13 (2). 97-102

3. Andarmoyo S. Pemberian Pendidikan Kesehatan Melalui Media Leaflet Efektif Dalam Peningkatan. :600-5.

4. Kementerian Kesehatan RI. Peduli TB, Indonesia Sehat. 2018.

5. Kementerian Kesehatan RI. Pemerintah Indonesia Akselerasi Eliminasi TB. 2018.

6. Enterprise J. Chatting Tanpa Batas Menggunakan Whatsapp. PT. Elex Media Komputindo; 2012.

7. Bohang FK. Pengguna Aktif Bulanan WhatsApp Tembus 15 Miliar. 2018.

8. Ekadinata N. Promosi Kesehatan Menggunakan Gambar Dan Teks Dalam Aplikasi Whatsapp Pada Kader Posbindu. 2017. 